\title{
Number of erythrocyte transfusions is more predictive than serum ferritin in estimation of cardiac iron loading in pediatric patients with acute lymphoblastic leukemia
}

\author{
Sule Unal ${ }^{\mathrm{a}, *}$, Mualla Cetin ${ }^{\mathrm{a}}$, Tuncay Hazirolan ${ }^{\mathrm{b}}$, Gokce Yildirim ${ }^{\mathrm{b}}$, Aytac Meral ${ }^{\mathrm{c}}$, \\ Ahmet Birbilen ${ }^{c}$, Erdem Karabulut ${ }^{\mathrm{d}}$, Selin Aytac ${ }^{\mathrm{a}}$, Betul Tavil ${ }^{\mathrm{a}}$, Baris Kuskonmaz ${ }^{\mathrm{a}}$, \\ Murat Tuncer ${ }^{\mathrm{a}}$, Fatma Gumruk ${ }^{\mathrm{a}}$ \\ a Hacettepe University, Division of Pediatric Hematology, Ankara, Turkey \\ ${ }^{\mathrm{b}}$ Hacettepe University, Department of Radiology, Ankara, Turkey \\ ${ }^{\mathrm{c}}$ Hacettepe University, Department of Pediatrics, Ankara, Turkey \\ ${ }^{\mathrm{d}}$ Hacettepe University, Department of Biostatistics, Ankara, Turkey
}

\section{A R T I C L E I N F O}

\section{Article history:}

Received 17 December 2013

Received in revised form 30 April 2014

Accepted 3 May 2014

Available online 14 May 2014

\section{Keywords:}

Pediatric

ALL

Iron

Cardiac

Hepatic

MRI

\begin{abstract}
A B S T R A C T
Background: Transfusions with packed erythrocytes is a common practice in pediatric patients with acute lymphoblastic leukemia (ALL) who are on chemotherapy. Since there is no physiological excretion mechanism for iron, the iron related to erythrocyte transfusions accumulates and may contribute to late cardiac, hepatic and endocrine complications in these patients.

Procedure: In order to evaluate the iron burden among pediatric patients with ALL and define the risk factors associated with higher iron loading, we evaluated 79 pediatric patients with ALL (36 were offtherapy). Cardiac and hepatic T2* were ordered to a total of $22(28 \%)$ patients who were either transfused with erythrocytes $\geq 10$ times $(n=11 ; 50 \%)$, had serum ferritin (SF) $\geq 1000 \mathrm{ng} / \mathrm{ml}(n=2 ; 9.1 \%)$ or both $(n=9$; 40.9\%).

Results: Half of the patients who were screened by T2* MRI had hepatic $\mathrm{T}^{*}<7 \mathrm{~ms}$ and six (27\%) of the patients had cardiac T2* $<20 \mathrm{~ms}$, indicating iron loading. Patients who had serum ferritin $<1000$ vs $\geq 1000 \mathrm{ng} / \mathrm{ml}$ had median cardiac T2* values of $28.3 \mathrm{~ms}(15-40)$ vs $21(7.9-36),(p=0.324)$; whereas hepatic T2* of $10.8(5.32-27)$ vs $4.7(2.2-36),(p=0.017)$. Patients who had erythrocyte transfusion $<10$ vs $\geq 10$ times had median cardiac T2* values of $34 \mathrm{~ms}(28-38)$ vs $23(7.93-40),(p=0.021)$; whereas hepatic $\mathrm{T} 2 *$ of $13.6(6.6-36)$ vs $5.32(2.2-27),(p=0.046)$.

Conclusions: Our results indicate that pediatric patients with ALL should be screened for transfusional iron load and the amount of erythrocyte transfusions seems to be a more reliable indication than serum ferritin levels to detect cardiac iron loading in these patients.
\end{abstract}

(C) 2014 Elsevier Ltd. All rights reserved.

\section{Introduction}

Patients with acute lymphoblastic leukemia (ALL) receive multiple erythrocyte transfusions during treatment that may lead to iron loading ending up with further increase in oxidative stress adding to that produced by the chemotherapeutics [1,2], contributing to long-term organ damage. Although, the data on the impacts of erythrocyte transfusion in patients with thalassemia and sickle cell

* Corresponding author at: Hacettepe University, Division of Pediatric Hematology, Ankara 06100, Turkey. Tel.: +90 312305 1170; fax: +90 3123112398 .

E-mail address: suleunal@hacettepe.edu.tr (S. Unal). are well-described [3,4], most of the data about the transfusional iron loading in patients with cancer are obtained from the adult patients with malignancies [5-7] or limited number of pediatric reports [8-10]. The transfusional hemosiderosis in these patients may exacerbate the potential cardiac, hepatic and endocrine late complications related to chemotherapy and is usually an underestimated risk factor. Additionally, the patients with iron overload have been reported to have increased risk of early mortality after hematopoietic stem cell transplantation and this was attributed to the increase in labile iron induced after conditioning regimen $[6,11]$.

The most commonly used parameters for iron status assessment are serum ferritin, iron, transferrin saturation; however, the 
use of serum ferritin may be inadequate to interpret the hepatic and cardiac iron loading in patients with ALL, because of the sustained acute-phase reaction and a deranged cytokine balance which may cause an increase in serum ferritin which itself is an acute phase reactant $[10,12,13]$. The gold-standard method for the estimation of cardiac iron loading is cardiac T2* MRI. Hepatic R2*/T2* MRI, being a non-invasive method, correlates well with the liver iron concentration measurements from the tissue obtained via liver biopsy $[14,15]$. Although, the indications to order for hepatic R2*/T2* and cardiac T2* are well-described in patients with thalassemia [3,14,15], it is less obscure and arbitrary, usually being according to the clinician's decision, such as selection of patients with serum ferritin level above $1000 \mathrm{ng} / \mathrm{ml}$ [9].

Herein, we present the iron loading characteristics among 79 pediatric patients with a diagnosis of ALL and interpret on the more predictive criteria on the tissue iron loading.

\section{Materials and methods}

In our study, the patients diagnosed to have ALL below 16 years of age, who were on follow-up for either treatment or after cessation of treatment and consented for the study were included $(n=83)$. The patients were enrolled between February 2013 and August 2013. The patients who underwent hematopoietic stem cell transplantation were not screened. Patients with clinical symptoms or signs of infection at time of assessment were not screened for the above mentioned tests at that visit and the evaluations were done when the infection status disappeared. None of the patients were carrier for or had active hepatitis B or hepatitis C infections. The personnel history prior to diagnosis of ALL revealed no erythrocyte transfusion history prior to diagnosis. None of the patients' history revealed a family member with hemochromatosis or hemoglobinopathy.

All the patients were on or off to St. Jude Total XV treatment protocol for ALL patients [16], except 2 relapsed patients who were receiving ALL-REZ-BFM 2002 [17]. Packed, irradiated, leukocyte depleted erythrocyte transfusions with hematocrit levels of $60-65 \%$ were transfused $10 \mathrm{ml} / \mathrm{kg}$, whenever hemoglobin level of the patient was below $9 \mathrm{~g} / \mathrm{dl}$ during induction, consolidation or maintenance phases of therapy.

All the patients were analyzed cross-sectionally for iron loading. Serum iron (SI), serum iron-binding capacity (SIBC), transferrin saturation (TS), serum ferritin and Creactive protein (CRP) were obtained. Patients with CRP levels above $2 \mathrm{mg} / \mathrm{dl}(n=4)$ were excluded from the analyses of iron status assessments, although they had no sign or symptoms for any infection and all biochemical iron status evaluations were made among the remaining 79 patients. The mean values of serum ALT, AST and creatinine at last three visits were used in statistical analyses.

Cardiac and hepatic T2* MRI were ordered to a total of $22(28 \%)$ patients who were either transfused with erythrocytes $\geq 10$ times $(n=11 ; 50 \%)$, had serum ferritin (SF) $\geq 1000 \mathrm{ng} / \mathrm{ml}(n=2 ; 9.1 \%)$ or both $(n=9 ; 40.9 \%)$. All MRI examinations were performed on 1.5 T MRI (Siemens Symphony 1.5 T MRI, Siemens Medical Solutions, Erlangen, Germany). Multiecho fast gradient echo sequence was used for both cardiac and hepatic iron evaluation. Hepatic and myocardial iron was obtained from T2 star value using CMR tools (Cardiovascular Imaging Solutions, London, UK).

None of the patients were on iron chelation treatment or phlebotomy program prior to either iron status monitoring or MRI evaluation.

The obtained data were evaluated by SPSS 15.0 package program. Normality test was performed to determine if the data were distributed in normal fashion. For comparison between two groups, 'independent samples $t$ test' and 'Mann-Whitney $U$ test' were used for groups with evenly and unevenly distributed data, respectively.

\section{Results}

The mean age of the patients at time of assessment for iron status was $120 \pm 59$ months (9-264) and 58 (73\%) were male. Of the 79 patients, $36(46 \%)$ have completed treatment, 2 (2\%) were relapsed patients on relapse protocol and the remaining 41 (52\%) were on maintenance treatment. Median number of packed erythrocyte transfusions was $7(1-46)$ at the time of assessment for iron loading. Of the 36 patients who have completed treatment 31 (6.1\%) were off-therapy for at least 1 year.

Mean ranges (in the patients evaluated) of the iron status parameters were as following: Mean SI concentration was $86.2 \pm 54.4 \mu \mathrm{g} / \mathrm{dl}(22-246)$ and mean SIBC was $216.5 \pm 85.5 \mu \mathrm{g} / \mathrm{dl}$ (6-369). The mean TS of the study group was $32.8 \pm 25.5$ (7.3-98.5). Serum ferritin was $\geq 200 \mathrm{ng} / \mathrm{ml}$ in 39 (49.4\%). The mean serum
Table 1

Clinical and laboratory characteristics of the patients.

\begin{tabular}{lcc}
\hline $\begin{array}{l}\text { Patients' characteristics } \\
(n=79)\end{array}$ & Mean \pm SD (range) & \\
\hline Serum iron $(\mu \mathrm{g} / \mathrm{dl})$ & $86.2 \pm 54.4(22-246)$ & 73 \\
Iron binding capacity & $216.5 \pm 85.5(6-369)$ & 227.5 \\
$\quad(\mu \mathrm{g} / \mathrm{dl})$ & $32.8 \pm 25.5(7.3-98.5)$ & 23.9 \\
Transferrin saturation & & \\
$\quad(\%)$ & $478.2 \pm 661.5(15.3-3657)$ & 203.8 \\
Serum ferritin $(\mathrm{ng} / \mathrm{ml})$ & $0.33 \pm 0.39(0.1-2)$ & 0.3 \\
Serum CRP & $10.4 \pm 8.7(2.2-36)$ & 7.6 \\
Hepatic T2* MRI $(\mathrm{ms})$ & $25.6 \pm 8.6(7.9-40)$ & 7 \\
Cardiac T2* MRI $(\mathrm{ms})$ & $10 \pm 9(1-46)$ & \\
Number of erythrocyte & & 33 \\
$\quad$ transfusions & $53.7 \pm 68.2(8-475)$ & 28 \\
Serum ALT (IU/L) & $34.1 \pm 19.9(15-138)$ & 0.38 \\
Serum AST (IU/L) & $0.4 \pm 0.15(0.17-0.96)$ & \\
Serum creatinine & & \\
$\quad(\mathrm{mg} / \mathrm{dl})$ & & \\
\hline
\end{tabular}

ferritin level was $478 \pm 661$ (15.3-3657) and median level was $203 \mathrm{ng} / \mathrm{ml}$. Mean serum CRP was $0.33 \pm 0.39 \mathrm{mg} / \mathrm{dl}(0.1-2)$ (Table 1$)$.

The mean values (range of values in the evaluated patients) of hepatic and cardiac T2* measurements were $10.4 \pm 8.7(2.2-36)$ and $25.6 \pm 8.6 \mathrm{~ms}(7.9-40)$, respectively (Table 1$)$. Half of the patients $(n=11)$ who were screened by T2* MRI $(n=22)$ had hepatic $\mathrm{T} 2 *<7 \mathrm{~ms}$ and six $(27 \%)$ of the patients had cardiac $\mathrm{T} 2 *<20 \mathrm{~ms}$, indicating iron loading. The severity of cardiac and hepatic iron loading was shown in Fig. 1. All the patients with cardiac iron loading had normal left-ventricle ejection fractions by trans-thoracic echocardiography.

None of the patients with serum ferritin $\geq 1000 \mathrm{ng} / \mathrm{ml}$ but $<10$ times erythrocyte transfusions were found to have iron overload in heart or liver. However, of the patients who were evaluated with T2* MRI because of high transfusional history but with serum ferritin $<1000 \mathrm{ng} / \mathrm{ml}, 27.3 \%$ and $18.2 \%$ of the patients were found to have hepatic and cardiac iron loading, respectively. Of the patients who were evaluated for MRI because of $\geq 10$ number of transfusions and $\geq 1000 \mathrm{ng} / \mathrm{ml}$ serum ferritin, $88.9 \%$ and $44.4 \%$ were found

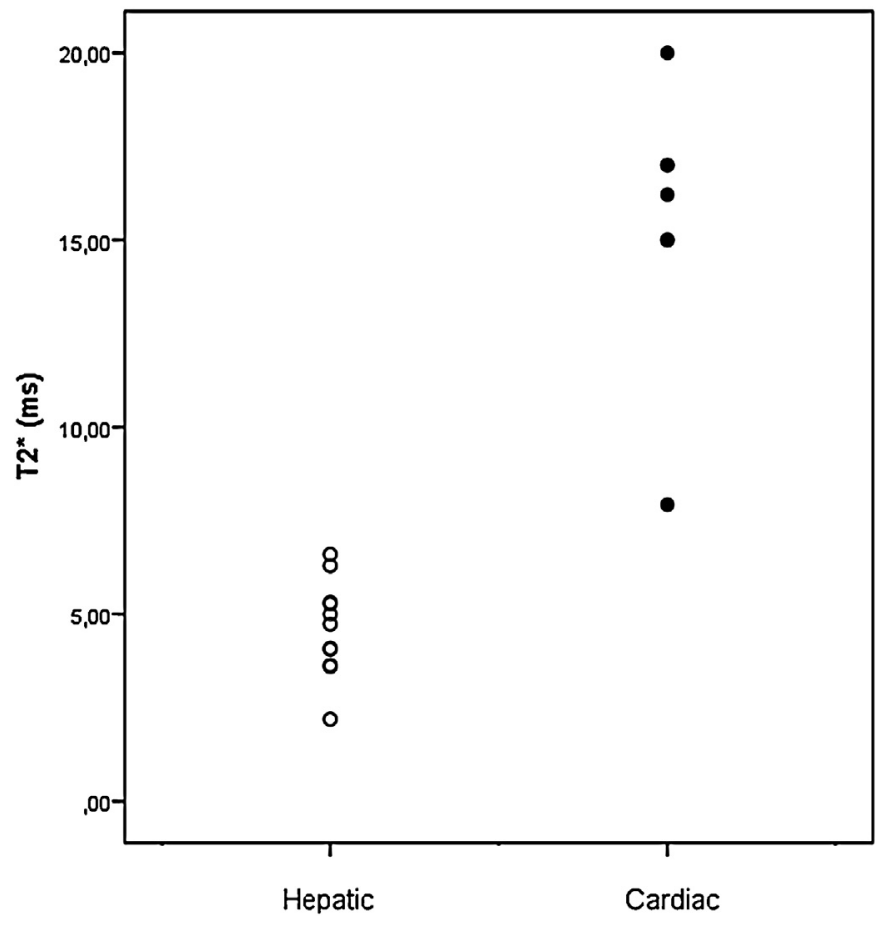

Fig. 1. Severity of cardiac and hepatic iron loading by $\mathrm{T} 2 *$ measurements. 


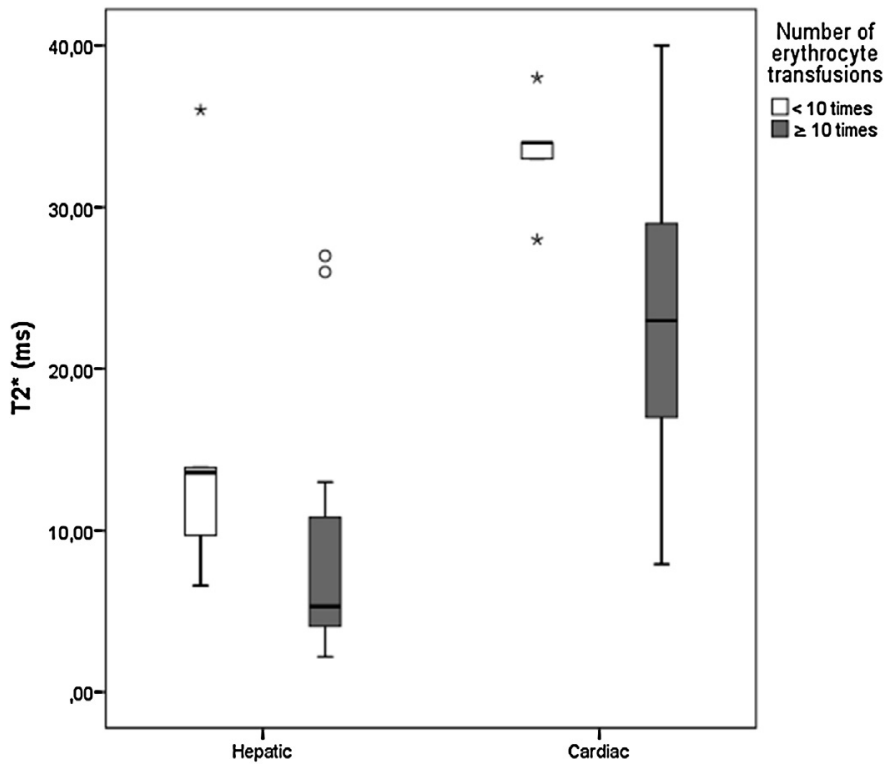

Fig. 2. The comparison of the hepatic and cardiac $\mathrm{T}_{2}^{*}$ values (ms) among patients who received $<10$ and $\geq 10$ times of erythrocyte transfusions.

to have hepatic and cardiac iron loading, respectively. Patients who had serum ferritin $<1000 \mathrm{vs} \geq 1000 \mathrm{ng} / \mathrm{ml}$ had median cardiac T2* values of $28.3 \mathrm{~ms}(15-40)$ vs $21(7.9-36),(p=0.324)$; whereas hepatic T2* of $10.8(5.32-27)$ vs $4.7(2.2-36),(p=0.017)$. Patients who had transfusion $<10$ vs $\geq 10$ had median cardiac T2* $^{*}$ values of $34 \mathrm{~ms}(28-38)$ vs 23 (7.93-40), $(p=0.021)$; whereas hepatic T2* of $13.6(6.6-36)$ vs $5.32(2.2-27),(p=0.046)$. The hepatic and cardiac $2^{*}$ values of patients who received $<10$ and $\geq 10$ times of erythrocyte transfusions were summarized in Fig. 2.

We evaluated the 8 patients who completed leukemia treatment and had MRI investigation according to age at diagnosis of leukemia. Of these patients, 4 were diagnosed before 10 years of age and were currently off therapy for median 1 year ( 6 months-42 months), only 1 patient was found to have cardiac iron loading (T2* $17 \mathrm{~ms}$ ) and none were found to have hepatic iron loading. Of the other 4 four patients who were diagnosed to have ALL after 10 years of age, currently completed treatment for median 18 months (12-60 months) and had MRI evaluation, 2 were found to have hepatic iron loading (T2* 5.27 and $6.3 \mathrm{~ms}$ ) and 1 patient was found to have cardiac iron loading ( $2 * 15 \mathrm{~ms}$ ).

The mean values of the last 3 visits' serum biochemistry values were analyzed in all the study groups of 79 patients (Table 1 ). Twenty-two $(27.8 \%)$ of the patients had ALT>50 IU/L. Of the 9 patients who had ALT > $100 \mathrm{IU} / \mathrm{L}, 2(22.2 \%)$ had hepatic T2* value $<7 \mathrm{~ms}$ and of the 13 patients who had ALT 50-100 IU/L, 2 (15.4\%) had hepatic $\mathrm{T}_{2} * 7 \mathrm{~ms}$ indicating iron loading. Of the 22 patients who had ALT > 50 IU/L, 4 (18\%) were patients were off the treatment (85-98 IU/L); but none of these 4 patients were found to have hepatic iron loading. Of the 11 patients who had $\mathrm{T}^{*}<7 \mathrm{~ms}$, 4 (36.3\%) were found to have ALT $>50 \mathrm{IU} / \mathrm{L}(92-217 \mathrm{IU} / \mathrm{L})$, but all of these patients were on chemotherapy protocol.

\section{Discussion}

According to our results, iron loading in pediatric patients with ALL is common, both during the anti-leukemic treatment and after cessation of therapy. The sources of iron loading in these patients have been reported as from erythrocyte transfusions and also leukemia itself $[9,10]$. Cessation of normal erythropoiesis, related to active disease or chemotherapy has been suggested to cause unused iron to accumulate [9]. Cardiac related mortality has been reported to increase $\geq 10$-fold among childhood cancer survivors [18-20]. Besides, the risk of late hepatic adverse events have also been stressed [18,21,22]. The iron overloading may contribute to these late morbidities in these patients, in addition to contributing potential endocrinopathies such as hypogonadotropic hypogonadism or hypothyroidism, similar to those reported in patients with $\beta$ thalassemia major $[23,24]$.

Our study was a cross-sectional study including both patients on and off of the leukemia treatment. We screened the patients with T2* MRI for hepatic and cardiac iron loading in case that they had either a history of erythrocyte transfusion $\geq 10$ times or serum ferritin $\geq 1000 \mathrm{ng} / \mathrm{ml}$ or both. Of the 22 patients out of 79 who fulfilled these requirements were evaluated with T2* MRI and 50\% and $27 \%$ were found to have hepatic and cardiac iron loading, respectively. These results indicate that the iron overloading is not uncommon among pediatric patients with ALL during both treatment phase and after cessation of therapy. In a recent study among pediatric cancer patients, the patients who were not transfused at baseline evaluation were not found to have cardiac or hepatic iron loading. On the other hand, these patients have been found to develop liver and cardiac iron loading in $63 \%$ and $6 \%$, respectively [18]. In this study, the serum ferritin values have not been in correlation with the MRI T2* values [18]. In a previous study, the amount of erythrocyte transfusions was found to be correlated with the ALL risk category [25]. In our study, we found out that the higher number of erythrocyte transfusions was a more reliable factor in estimation of the cardiac iron loading compared to serum ferritin measurements $(p=0.021$ vs 0.324 ). Additionally, none of the patients with serum ferritin $\geq 1000 \mathrm{ng} / \mathrm{ml}$ as the sole indication were found to have cardiac or hepatic iron loading, whereas the patients who were screened with MRI just because of transfusion number $\geq 10$, but had normal serum ferritin levels, $27.3 \%$ and $18.2 \%$ were found to have hepatic and cardiac iron loading, respectively. We suggest that patients who are on or off the anti-leukemic treatment might be evaluated with $\mathrm{T}^{*}$ MRI for cardiac and hepatic iron loading despite they had serum ferritin levels below $1000 \mathrm{ng} / \mathrm{ml}$, but they received $\geq 10$ times of erythrocyte transfusions.

In a recent study, the patients who had a large increase in body surface area (BSA) were found to be more protected against the iron loading than those with a little or no change or a decrease in their BSA and concluded that the younger patients treated for cancer may not be as high risk for persistent iron loading as patients who were treated older and completed their growth spurt [8]. In our study, we evaluated the patients who completed leukemia treatment and had MRI investigation according to age at diagnosis of leukemia. Although, the number of patients in each group was a limiting factor, 1 out of 4 patients (25\%) who were diagnosed before 10 years of age with leukemia and were evaluated with MRI after cessation of treatment according to or study indications was found to have tissue iron loading, whereas of the 4 patients who were diagnosed to have ALL after 10 years of age and was evaluated with MRI after cessation of treatment, 3 (75\%) were found to have either cardiac or hepatic iron loading. This finding may indicate that the time of diagnosis of ALL may affect the long term iron loading in these patients. The growth spurt may cause a decline in the stored iron in patients who were diagnosed with ALL before 10 years of age related to increased requirement for iron due to expansion of blood volume. However, our sample size is limited to make such a definitive conclusion.

The absence for a genetic analyses to rule-out genetic causes of hemochromatosis is a limitation of our study, which may have contributed to serum ferritin levels and tissue iron loading. However, family history revealed no family member with a diagnosis of hemochromatosis or any disease related to iron overloading. Additionally, serum ferritin is an acute phase reactant that may increase in the presence of inflammation. In order to rule-out the elevations 
in serum ferritin that may be related to infection, the blood analyses were made when patients were free from any symptom or sign of infection. Besides, we excluded the data of the patients from analyses if they had serum CRP above $2 \mathrm{mg} / \mathrm{dl}$, even though they had no signs of infection. The hypertransaminasemia in some of the patients may not be solely attributed to hepatic iron loading, but may be related to the toxicities of the chemotherapy regimens.

In conclusion, our study indicates that pediatric patients with ALL should be screened for transfusional iron load and the amount of erythrocyte transfusions seem as a more reliable indication than serum ferritin levels to detect cardiac or hepatic iron loading in these patients. Secondly, especially the patients who were diagnosed to have ALL before 10 years of age are more at risk to have persistent iron loading after cessation of treatment compared to those who were diagnosed after 10 years of age.

\section{Conflict of interest statement}

The authors declare the absence of any conflict of interest.

\section{Acknowledgement}

All authors contributed equally at the conception and design of the study, or acquisition of data, or analysis and interpretation of data, drafting the article or revising it critically for important intellectual content, final approval of the version to be submitted.

\section{References}

[1] Ruccione KS, Mudambi K, Sposto R, Fridey J, Ghazarossian S, Freyer DR. Association of projected transfusional iron burden with treatment intensity in childhood cancer survivors. Pediatr Blood Cancer 2011;59:697-702.

[2] Conklin KA. Chemotherapy-associated oxidative stress: impact on chemotherapeutic effectiveness. Integr Cancer Ther 2004;3:294-300.

[3] Shander A, Cappellini MD, Goodnough LT. Iron overload and toxicity: the hidden risk of multiple blood transfusions. Vox Sang 2009;97:185-97.

[4] Ault P, Jones K. Understanding iron overload: screening, monitoring, and caring for patients with transfusion-dependent anemias. Clin J Oncol Nurs 2009;13:511-7.

[5] Barton JC, Bertoli LF. Transfusion iron overload in adults with acute leukemia: manifestations and therapy. Am J Med Sci 2000;319:73-8.

[6] Armand P, Sainvil MM, Kim HT, Rhodes J, Cutler C, Ho VT, et al. Pretransplantation iron chelation in patients with MDS or acute leukemia and iron overload undergoing myeloablative allo-SCT. Bone Marrow Transplant 2013;48:146-7.

[7] Franchini M, Gandini G, Veneri D, de Matteis G, Federici F, Solero P, et al. Efficacy and safety of phlebotomy to reduce transfusional iron overload in adult, longterm survivors of acute leukemia. Transfusion 2004:44:833-7.

[8] Amid A, Barrowman N, Vijenthira A, Lesser P, Mandel K, Ramphal R. Risk factors for hyperferritinemia secondary to red blood cell transfusions in pediatric cancer patients. Pediatr Blood Cancer 2013;60:1671-5.
[9] Olcay L, Hazirolan T, Yildirmak Y, Erdemli E, Terzi YK, Arda K, et al. Biochemical, radiologic, ultrastructural, and genetic evaluation of iron overload in acute leukemia and iron-chelation therapy. J Pediatr Hematol Oncol 2013 [Epub ahead of print].

[10] Halonen P, Mattila J, Suominen P, Ruuska T, Salo MK, Mäkipernaa A. Iron overload in children who are treated for acute lymphoblastic leukemia estimated by liver siderosis and serum iron parameters. Pediatrics 2003;111: 91-6.

[11] Sahlstedt L, Ebeling F, von Bonsdorff L, Parkkinen J, Ruutu T. Non-transferrin bound iron during allogeneic stem cell transplantation. $\mathrm{Br} \mathrm{J}$ Haematol 2001:113:836-8.

[12] Birgegard G, Hallgren R, Killander A, Strömberg A, Venge P, Wide L. Serum ferritin during infection. A longitudinal study. Scand J Haematol 1978;21: 333-40.

[13] Siimes MA, Wang WC, Dallman PR. Elevated serum ferritin in children with malignancies. Scand J Haematol 1977;19:153-8.

[14] Origa R, Danjou F, Cossa S, Matta G, Bina P, Dessì C, et al. Impact of heart magnetic resonance imaging on chelation choices, compliance with treatment and risk of heart disease in patients with thalassaemia major. $\mathrm{Br} \mathrm{J}$ Haematol 2013;163:400-3.

[15] Youssef DM, Fawzy Mohammad F, Ahmed Fathy A, Aly Abdelbasset M. Assessment of hepatic and pancreatic iron overload in pediatric Beta-thalassemic major patients by $\mathrm{t} 2 *$ weighted gradient echo magnetic resonance imaging. ISRN Hematol 2013;2013:496985.

[16] Rubnitz JE, Campbell P, Zhou Y, Sandlund JT, Jeha S, Ribeiro RC, et al. Prognostic impact of absolute lymphocyte counts at the end of remission induction in childhood acute lymphoblastic leukemia. Cancer 2013;119:2061-6.

[17] Bader P, Kreyenberg H, Henze GH, Eckert C, Reising M, Willasch A, et al. Prognostic value of minimal residual disease quantification before allogeneic stem-cell transplantation in relapsed childhood acute lymphoblastic leukemia: the ALLREZ BFM Study Group. J Clin Oncol 2009;27:377-84.

[18] de Ville de Goyet M, Moniotte S, Robert A, Dupont S, Vermylen C, Veyckemans $\mathrm{F}$, et al. Iron overload in children undergoing cancer treatments. Pediatr Blood Cancer 2013;60:1982-7.

[19] Mulrooney DA, Yeazel MW, Kawashima T, Mertens AC, Mitby P, Stovall M, et al. Cardiac outcomes in a cohort of adult survivors of childhood, adolescent cancer: a report from the childhood cancer survivor study. Br Med J 2009; 339:b4606.

[20] Armstrong GT, Liu Q, Yasui Y, Neglia JP, Leisenring W, Robison LL, et al. Late mortality among 5-year survivors of childhood cancer: a summary from the childhood cancer survivor study. J Clin Oncol 2009;27:2328-38.

[21] Mulder RL, van Dalen EC, Van den Hof M, Bresters D, Koot BG, Castellino SM et al. Hepatic late adverse effects after antineoplastic treatment for childhood cancer. Cochrane Database Syst Rev 2011;7:CD008205.

[22] Mulder RL, Kremer LCM, Koot BGP, Benninga MA, Knijnenburg SL, van der Pal $\mathrm{HJ}$, et al. Surveillance of hepatic late adverse effects in a large cohort of longterm survivors of childhood cancer: prevalence and risk factors. Eur J Cancer 2013;49:185-93.

[23] De Sanctis V, De Sanctis E, Ricchieri P, Gubellini E, Gilli G, Gamberini MR Mild subclinical hypothyroidism in thalassaemia major: prevalence, multigated radionuclide test, clinical and laboratory long-term follow-up study. Pediatr Endocrinol Rev 2008;6(Suppl. 1):174-80.

[24] Borgna-Pignatti C, Rugolotto S, De Stefano P, Zhao H, Cappellini MD, Del Vecchio GC, et al. Survival and complications in patients with thalassemia major treated with transfusion and deferoxamine. Haematologica 2004;89: 1187-93.

[25] Ktena YP, Athanasiadou A, Lambrou G, Adamaki M, Moschovi M. Iron chelation with deferasirox for the treatment of secondary hemosiderosis in pediatric oncology patients: a single-center experience. J Pediatr Hematol Oncol 2013;35:447-50 